\title{
Linguistic Choices for Literary Dialectics: A Coming Together of Divergent Entities
}

\author{
Dr. Sabitha S. R. Najeeb \\ Ms. Manar AlDawood \\ Department of English
}

doi: 10.19044/esj.2016.v12n32p269 URL:http://dx.doi.org/10.19044/esj.2016.v12n32p269

\begin{abstract}
Literature involves the manipulation of language for creative purposes and the discipline which fosters this synergic relationship between literature and language is termed stylistics. The purpose of this article is to show how it is possible to bridge the divide between language and literature by using the analytical techniques available within this sub-discipline of language study. Stylistics aims to interconnect linguistic form and literary effect, and also account for what it is that readers respond to when they praise the quality of a particular piece of writing. This article attempts to depict how the knowledge of linguistic intricacies can affect the reader's interpretation. It also discusses how linguistic form relates to literary effect by analysing "Domination of Black", by the renowned American poet Wallace Stevens. We aim to show that a linguistic approach to the analysis of a literary text does not have to mean that interpretation is disregarded. On the contrary, stylistic analysis can often illuminate why a particular literary text is regarded so highly.
\end{abstract}

Keywords: Literature, Language, Linguistics, Stylistics, Analysis

\section{Introduction}

Contemporary Age has attested the emergence of stylistics as a powerful linguistic tool for analyzing literary texts. The relationship between the study of literature and the study of language has often been one of unease. While literary critics have censured the austere approach used by scholars of language in their analyses of literary texts, linguists have arraigned litterateurs of being too vague and subjective in the analyses they produced. The insight of Jakobson (1960) who has frequently cited the relationship between linguistics and literary studies is worth noting here. He states that: 
If there are some critics who still doubt the competence of linguistics to embrace the field of poetics, I privately believe that ...linguists have been mistaken for an inadequacy of the linguistic science itself. All of us here, however, definitely realice that a linguist deaf to the poetic function of language and a literary scholar indifferent to linguistic problems and unconversant with linguistic methods are equally flagrant anachronisms.

This article attempts to depict how the knowledge of linguistic intricacies can affect the reader's interpretation. It also discusses how linguistic form relates to literary effect by analyzing "Domination of Black", composed by the eminent American poet Wallace Stevens. We aim to show that a linguistic approach to the analysis of a literary text does not have to mean that interpretation is disregarded. On the contrary, we would suggest that stylistic analysis can often illuminate why a particular literary text is regarded so highly. Furthermore, it is also claimed that attention to these underlying linguistic intricacies brings about a better understanding and appreciation of the poem by the reader either.

\section{Literature Review}

Literary analysis and linguistic analysis were seen as two circuitous entities earlier. Consequently, the literary artist believed that weighing literature on the scale of linguistics amounted to intruding on the portal of literature. However, Lawal (1997) advocates for a symbiotic relationship between linguistics and literature which throws light to the incontrovertible bond between language and literature. Corroborating this, Brain (1993) testifies that "literature is a manifestation of verbal culture and cannot be filtered out or separated from language.” Linguistics empowers us to "trust the text" (Sinclair 1992), in other words, to interpret the text, rather than impose interpretations upon it. In short, linguistics is a timely reply to theorists who seem to have capitulated the text in favor of an equivocal perception of literary analysis, which, rather than seeing texts as aesthetically meaningful artefacts in themselves, treat them as largely interchangeable products of a discursive system.

Widdowson (1975) considers stylistics as a buffer between language and literature. He argues that "stylistic/semantic analysis shades imperceptibly into literary appreciation". While Bloomfield (1976) is of the view that stylistics is the study or interpretation of the distinctive linguistic elements in the writing of a text, Leech (1969) defines stylistics as "the study of the use of language in literature". This means that it is responsive with the study of both linguistics and literature. Stylistics studies the language and creativity in the language by surveying if the rules of the language are or are not perceived to make particular effect in the text. It focuses on analyzing literary texts with the use of linguistic description. 
Stylistics explains the peculiar choices made by the poet in the use of language. It acknowledges the skills of the writer on the assumption that every decision made in the production of a text is deliberate, despite whether these decisions were made consciously or unconsciously. Acquah (2010) notes that the message a writer addresses maybe similar to or even the same as the message addressed by other writers, but what makes his/her work uniquely his/her own is his/her technique. And as far as technique is concerned, a stylistic approach, which involves a close study of the linguistic organization of a writer's work, "will yield far greater insights into his art and message" (Acquah). This assumption recognizes that there are often several ways in which a writer can use the resources of a language to express the same experience or event in a text. In the creative process, literary writers either consciously or unconsciously choose certain linguistic items over others to represent an experience or event for stylistic effects.

Consequently, stylistics aims to interconnect linguistic form and literary effect, and also account for what it is that readers respond to when they shower accolades to the quality of a particular piece of writing. It is important to assume that every element of any piece of writing has a possible interpretative significance. In this context, it is natural to ponder if this is actually the case or to ask whether the readers really infer meaning from every bit of a text. Researchers such as Van Peer (1986) have validated that readers do indeed pick up on the smallest details of a text and use them to construct a meaningful interpretation.

\section{Domination of Black}

At night, by the fire, The colors of the bushes And of the fallen leaves,

Repeating themselves,

Turned in the room,

Like the leaves themselves

Turning in the wind.

Yes: but the color of the heavy hemlocks

Came striding.

And I remembered the cry of the peacocks.

The colors of their tails

Were like the leaves themselves

Turning in the wind,

In the twilight wind.

They swept over the room,

Just as they flew from the boughs of the hemlocks 
Down to the ground.

I heard them cry -- the peacocks.

Was it a cry against the twilight

Or against the leaves themselves

Turning in the wind,

Turning as the flames

Turned in the fire,

Turning as the tails of the peacocks

Turned in the loud fire,

Loud as the hemlocks

Full of the cry of the peacocks?

Or was it a cry against the hemlocks?

Out of the window,

I saw how the planets gathered

Like the leaves themselves

Turning in the wind.

I saw how the night came,

Came striding like the color of the heavy hemlocks

I felt afraid.

And I remembered the cry of the peacocks.

\section{Stylistics aspects of Domination of Black}

Like many of Stevens' poems, "Domination of Black” appears to induce in the subject a sense of the individual's insignificance and powerlessness. A feeling of terror and fear is intertwined in the poem, especially towards the end. The treatment of darkness adds to the feeling of terror and darkness. There is a dynamic feel to the poem and, the readers are presented with a set of random images (e.g. night, twilight, flames) and actions. An analysis of the lexical features makes it possible for an overall comprehension of the poem.

\section{Semantic groups as connectives between man and nature}

The first lexical feature to be considered is the open class words in the poem. Open class words are those which carry the majority of meaning in a language, as opposed to closed class (grammatical) words such as determiners (e.g. this, that, the) and prepositions (e.g. in, at, on). Closed class words act like sentence 'glue' and link together open class words in meaningful arrangements (sentences). Table 1 shows how the open class words are distributed throughout the poem, and whether they are nouns, verbs, adjectives or adverbs. 


\begin{tabular}{|c|c|c|c|}
\hline Nouns & Main Verbs & Adjectives & Adverbs \\
\hline Night - 2 & Repeating & Fallen & At night \\
\hline Fire - 3 & Turned - 3 & heavy & Out \\
\hline Color - 2 & Turning - 6 & loud & \\
\hline Wind - 5 & Striding - 2 & afraid & \\
\hline Hemlocks - 4 & Cry - 6 & & \\
\hline Peacocks - 5 & Swept & & \\
\hline Tails - 2 & flew & & \\
\hline Bough & Gathered & & \\
\hline Ground & Came - 2 & & \\
\hline Twilight - 2 & Remembered - 2 & & \\
\hline Window & heard & & \\
\hline planets & Saw - 2 & & Total no. of \\
\hline Colors - 2 & & & occurrences - 2 \\
\hline Leaves - 5 & & & Total no. of \\
\hline Room - 2 & & occurrences - 4 & \\
\hline flames & & & \\
\hline Total no. of & Total no. of & & \\
\hline occurrences - 39 & occurrences - 28 & & \\
\hline
\end{tabular}

Table 1: Distribution of open class words in Domination of Black

We can see from the above table that the poem consists mainly of nouns and verbs. The nouns are mostly concrete - that is, they refer to physical objects. It is possible to divide the nouns into two rough areas of meaning, or semantic fields. Table 2 shows how we might do this:

\begin{tabular}{|c|c|}
\hline Nouns related to nature & Nouns related to humans \\
\hline $\begin{array}{c}\text { night, fire, color, wind, flames, hemlocks, } \\
\text { peacocks, tails, bough, ground, twilight, } \\
\text { planets, leaves }\end{array}$ & room, window \\
\hline
\end{tabular}

Table 2: Distribution of nouns within two basic semantic classes

The mixture in the poem of nouns belonging to these two different semantic classes could be said to account for what we perceive as an interconnection between nature and man. The initial impression of the poem was that there was some kind of conflict between these two elements and this is explained in part by the above table. The two nouns related to humans room and window - could function as a connecting link between the natural elements inside and outside the room, and might be seen to connect the two semantic classes.

\section{Verbs}

The verbs, for the most part, are in the simple present, which implies something that is continually true. The verbs in the poem create a sense of continuity as we read it. They also contribute to our understanding of the 
poem as a self-reflective one. We have present simple verbs such as "cry", which is repeated six times [lines 10, 18, 19, 27, 28, 36], and present progressive forms such as "turning" (lines 7, 13, 21, 22, 24, 32) and "striding" (lines 9, 34). In addition to helping to establish the sense of immediacy, the progressive present forms indicate the ongoing nature of the actions. This contributes to the idea of the inevitable cyclical nature of day and night, the world of the living and the world of the dead. This is also reinforced by the adverb of time (at night) and adverb of place (out) which conveys a sense of impending trepidation. The fact that all the verbs are in the active mood refers to the poet and indicates the way in which he is the observer/victim of events rather than the originator of them. The participles and other parts of the syntax reinforce the impression created by the simple verbs.

\section{Repetition and Alliteration}

Though the repetition of the words "cry", "turn" and "stride" throughout the poem builds redundance into the text, as a rhetorical device, repetition can be used for emphasis or reinforcement of a key idea - these words reinforce the cyclic alternating that occurs throughout nature. The middle stanza of "Domination of Black" also experiments with a selfreflexive expansion of the stanza, as five successive lines begin with anaphoric “Turning" or "Turned". The repetition has three effects reinforcement, redundance, overstatement. When used positively, it works to build up and emphasize the description or the relationship described. When it works negatively it has the effect of undermining what has been declared. Either way, repetition is a powerful tool which bears upon the nature of the text and of the poet's desire to persuade and convince himself that normal expectations must be suspended.

An analysis of the following lines brings out the effectiveness of the rhythm.

Repeating themselves,

Turned in the room,

Like the leaves themselves,

Turning in the wind.

The two short syllables in the middle of the first of those lines are followed by the thumping long drawn-out ones, with a line-break stretching out 'selves/turned' further still, and then more anapestic (short-short-long) syllable sets broken by the near-repeated 'selves/turn' once again on the bridge of third and fourth lines. The 'turning' gains emphasis from the controlled rhythm and continues to do so throughout the poem. The alliterative use of language in "heavy hemlocks" and "like (the) leaves" remarkably affects the readers` sensations while the author`s description of 
the scene goes beyond the literal. The overarching approach of night, fear and death dominates the poem. Repetition is integral here as it creates a sense of inevitability, an increasing weight of doom, a mesmerizing force. The hemlocks have an aura of death. Those peacocks with their awful cry act partly as a warning, partly as protest, partly as helplessness. And yet the poem is spectacular in its beauty.

\section{Conclusion}

A linguistic analysis of a literary work in this vein is simple, straightforward, and rests on the main principle that the analyst must examine closely the linguistic choices that have been made for literary reasons by the poet. The syntactic turnings revise earlier readings as we turn the ends of lines, and these syntactic turnings are emblematic of the entire poem, which keeps turning back retrospectively and revising itself as it moves forward, repeating. The context becomes cosmic by Stevens` sudden change of perspectives in the last stanza. It becomes a question of being at home in the universe, under those planets that should also turn, like so much else in this poem. They do not turn. Instead, they "gather". At stake are both a discussion of the meaning of the poem, and, accordingly, a detailed description of what constitutes the language and style of the writer as literary. Furthermore, it is to be noted that attention to these underlying linguistic intricacies brings about a better understanding for the reader either consciously or unconsciously. The above study proves that a linguistic approach to the analysis of a literary text does not have to mean that interpretation is disregarded. On the contrary, we would suggest that stylistic analysis can often illuminate why a particular literary text is regarded so highly. Language and style, in analysis such as this, are effectively labels for the more traditional concept of diction: what writers write-and the linguistic choices they make-are as important as the 'meaning' of the text.

\section{References:}

1. Acquah, Leonard. (2010). A stylistic study of character and characterization in T. O. Echewa's The Land's Lord. In J. K. S Makokha, R. Barasa \& A. Daramola (Eds.), Tales, tellers and taleMaking: Critical studies on literary stylistics and narrative style in contemporary African literature. Saarbrüken, Germany: VDM Verlag Dr. Müller.

2. Bloomfield, Morton W. (1976). "Stylistics and the Theory of Literature”. New Literary History 7 (2).

3. Brian, Lamont. (1993). First Impression. Edinburgh: Penbury Press. 
4. Jakobson, Roman. (1960). Linguistics and Poetics. In T. Sebeok (Ed.), Style in Language. Cambridge: Massachusetts Institute of Technology Press.

5. Lawal, Adebayo. (1997) "Semiotic Perspectives on the Place of Linguistics Competence". Stylistics in Theory and Practice. Ilorin; Paragon Books.

6. Leech, Geoffrey N. (1969) A Linguistic Guide to English Poetry, London: Longman.

7. Peer, Willie van. (1986). Stylistics and Psychology: Investigations of Foregrounding. London: Croom Helm.

8. Sinclair, John. (2004): “Trust the Text” in: Ronald Carter (ed.), Trust the Text: Language, Corpus and Discourse. London: Routledge.

9. Stevens, Wallace (1995). "Domination of Black". Scholes Robert, Comley Nancy R. and Ulmer Gregory L. eds. Text Book: An Introduction to Literary Language. New York: St. Martin's Press.

10. Widdowson Henry G. (1975). Stylistics and the Teaching of Literature, London; Longman. 